\title{
MODELO DE PONTO CRÍTICO PARA ESTIMAR OS DANOS CAUSADOS PELO OÍDIO EM CEVADA
}

\author{
ERLEI M. REIS, LAÉRCIO L. HOFFMANN \& MARTA M. C. BLUM \\ Universidade de Passo Fundo, Faculdade de Agronomia e Medicina Veterinária, Cx. Postal 611, \\ CEP 99001-970, Passo Fundo, RS, e-mail: erleireis@uol.com.br
}

(Aceito para publicação em 26/09/2002)

Autor para correspondência: Erlei Melo Reis

REIS, E.M., HOFFMANN L.L. \& BLUM, M.M.C. Modelo de ponto crítico para estimar os danos causados pelo oídio em cevada. Fitopatologia Brasileira 27:644-646. 2002.

\begin{abstract}
RESUMO
Em experimento conduzido no campo com a cultivar cevada (Hordeum vulgare) BR 2 gerou-se o gradiente do oídio pelo uso de fungicidas em tratamento de sementes de modo a se obter um gradiente da incidência da doença e do rendimento de grãos. Com esses dados, através de análise de regressão, obteve-se um modelo que permite estimar o rendimento de grãos da cevada, em função

da intensidade do oídio, em diferentes estádios fenológicos da cultura. $\mathrm{O}$ melhor modelo foi representado pela equação $\mathrm{Y}=$ $2.978,3$ - 7,75 X $\left(\mathrm{R}^{2}\right.$ de 0,83) para o estádio de afilhamento. A redução máxima no rendimento de grãos foi de $28,03 \%$.

Palavras-chave adicionais: Hordeum vulgare, danos, Blumeria graminis.

\section{ABSTRACT \\ A critical-point model to estimate yield losses caused by powdery milew in barley}

In an experiment carried out in the field with the barley (Hordeum vulgare) cultivar BR 2 the gradient of powdery mildew incidence and grain yield were generated by the use of fungicide in seed treatment. Data was submitted to regression analysis. A critical point model was obtained that may be used to estimate barley grain yield, in relation to powdery mildew incidence, at

different host growing stages. The best model was represented by the equation $\mathrm{Y}=2,978.3-7.75 \mathrm{X}\left(\mathrm{R}^{2}=0.83\right)$ at tillering. The maximum grain yield reduction was $28.03 \%$. This equation may be also be used to calculate the economic damage threshold for powdery mildew in barley cultivars with susceptibility similar to BR 2.
\end{abstract}

A cevada (Hordeum vulgare L.) é o segundo cereal de inverno de maior expressão econômica para a agricultura no sul do Brasil. Na safra 2001, cultivou-se, aproximadamente, 140.000 ha com um rendimento médio de 2,8 t.ha $^{-1}$ (Recomendações, 1999).

Devido às condições climáticas e à suscetibilidade das cultivares, várias doenças fúngicas ocorrem nessa cultura, destacando-se o oídio, cujo agente etiológico é Blumeria graminis E. O. Speer f. sp. hordei Em. Marchal. A cultivar de cevada BR 2, que ocupa a maior área cultivada, é altamente suscetível ao oídio, resistente a mancha-em-rede [Drechslera teres (Sacc.) Shoem.] e suscetível a mancha marrom [Bipolaris sorokinian (Sacc.) Shoem.] (Recomendações, 1999). Epidemias do oídio ocorrem em todas as safras agrícolas da cevada, exigindo o uso de fungicidas para seu controle emergencial a partir do estádio do afilhamento. Apesar disso ainda não foram devidamente quantificados os danos causados pela doença em cultivares de cevada, no Brasil. Por outro lado, Mahtre (1977) cita que o oídio tem potencial de causar redução na produção de grãos na cevada de até $40 \%$.

As estratégias de controle dessa doença concentramse no desenvolvimento de cultivares com resistência genética e no uso de fungicidas em tratamento de sementes ou pulve- rizados nos órgãos aéreos do hospedeiro (Recomendações, 1999).

No caso do oídio da cevada, os primeiros trabalhos de pesquisa deveriam ter procurado quantificar os danos por ser uma doença epidêmica que se manifesta com alta intensidade todos os anos, porém são poucas as informações confiáveis disponíveis na literatura que quantificaram os efeitos das doenças sobre o rendimento de grãos.

Vários modelos podem ser utilizados para estimar danos de doenças em plantas, sendo um deles o de ponto crítico. Segundo Bergamin Filho \& Amorim (1996), no modelo de ponto crítico é possível identificar um determinado estádio de desenvolvimento do hospedeiro no qual a intensidade de doença presente está correlacionada com o dano futuro. Esse modelo, por ser simples, tem aplicação prática para estimar os danos que uma doença causa no hospedeiro em função do estádio de desenvolvimento fenológico e da intensidade da moléstia.

O objetivo deste trabalho foi quantificar o efeito do oídio no rendimento de grãos numa cultivar de cevada suscetível de modo a gerar equações para estimar os danos, segundo o modelo de ponto crítico, causados em função da intensidade da doença em diferentes estádios fenológicos do hospedeiro. 
Modelo de ponto crítico para estimar os danos causados pelo...

O presente trabalho foi conduzido na safra de inverno de 1996 no município de Coxilha - RS, utilizando-se a cultivar de cevada BR 2. Para alcançar os objetivos propostos, procurou-se gerar o gradiente da intensidade do oídio pelo uso de fungicida conforme sugerido por Sah \& MacKenzie (1987). Desse modo, utilizou-se o fungicida triticonazol, triazol sistêmico para tratamento de sementes, indicado para o controle do oídio. Foram utilizadas as seguintes quantidades de ingrediente ativo (i.a.) para $100 \mathrm{~kg}$ de sementes: 0, 20, 40, 60,80 e $100 \mathrm{~g}$. A semeadura foi realizada com semeadora de parcelas no sistema plantio direto e em área com rotação de culturas.

As parcelas foram constituídas por 19 linhas, espaçadas de $17 \mathrm{~cm}$ e $5 \mathrm{~m}$ de comprimento. Na adubação, utilizouse $270 \mathrm{~kg} \cdot \mathrm{ha}^{-1} \mathrm{e}$ a adubação nitrogenada em cobertura de 100 $\mathrm{kg} . \mathrm{ha}^{-1}$ de uréia aplicada quando as plantas encontravam-se no estádio de afilhamento. Obedeceram-se as recomendações técnicas da cultura na condução desse experimento (Recomendações, 1999).

As avaliações da intensidade do oídio foram baseadas na determinação da incidência foliar da doença, considerandose infetada a folha que apresentasse uma colônia de sinais visíveis da colonização. A patometria foi realizada nos estádios fenológicos de afilhamento, de elongação, de emborrachamento e de floração (Zadoks et al.,1974) em 50 afilhos coletados ao acaso por parcela. Os tratamentos foram distribuídos nas parcelas no delineamento em blocos ao acaso com quatro repetições.

No final do ciclo da cultura foi feita a colheita mecânica com colhedora de parcelas Wintersteiger, a secagem, a limpeza e a pesagem dos grãos, sendo o rendimento expresso em kg.ha- ${ }^{-1}$.

Os dados de rendimento de grãos e de incidência foliar do oídio foram submetidos à análise de regressão. As análises de regressão entre o rendimento de grãos e a incidência do oídio geraram equações lineares. Em relação ao rendimento de grãos houve uma relação negativa com a incidência do oídio, nos diferentes estádios fenológicos avaliados (Figura $1)$.

O dano máximo no rendimento de grãos foi de $28,03 \%$ inferior aos citados por Mahtre (1977). É interessante comparar esse montante de danos com os causados pelo oídio em trigo (Triticum aestivum L.) conforme relatados por Casa et al. (2001). Esses autores quantificaram valores de até 32\% na cultivar de trigo BR 23 e de $79 \%$ na cultivar OR 1, portanto superiores aos detectados em cevada no presente trabalho.

Os coeficientes de determinação $\left(R^{2}\right)$ variaram de 0,62 a 0,83 , sendo os mais elevados nos estádios de afilhamento e de emborrachamento (Figura 1, A e C); todos significativos a diferentes valores de probabilidade). No caso do afilhamento (Figura 1, A), por exemplo, num rendimento potencial de $2.978,3 \mathrm{~kg} \cdot \mathrm{ha}^{-1}$, para cada $1 \%$ de incidência do oídio, segundo esse modelo, ocorreu redução de $7,75 \mathrm{~kg}$.ha ${ }^{-1}$ no rendimento de grãos. Essa proporção corresponde a uma redução de 2,6 $\mathrm{kg} \cdot \mathrm{ha}^{-1}$ para cada $1.000 \mathrm{~kg}$ de grãos produzidos. Esse coeficiente de dano pode ser utilizado na fórmula de Munford

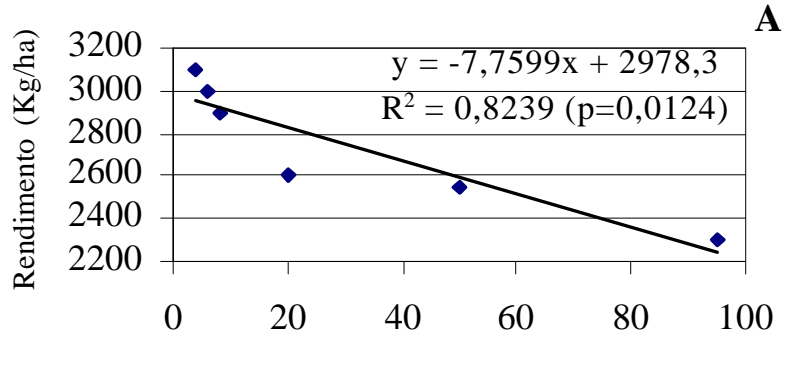

B
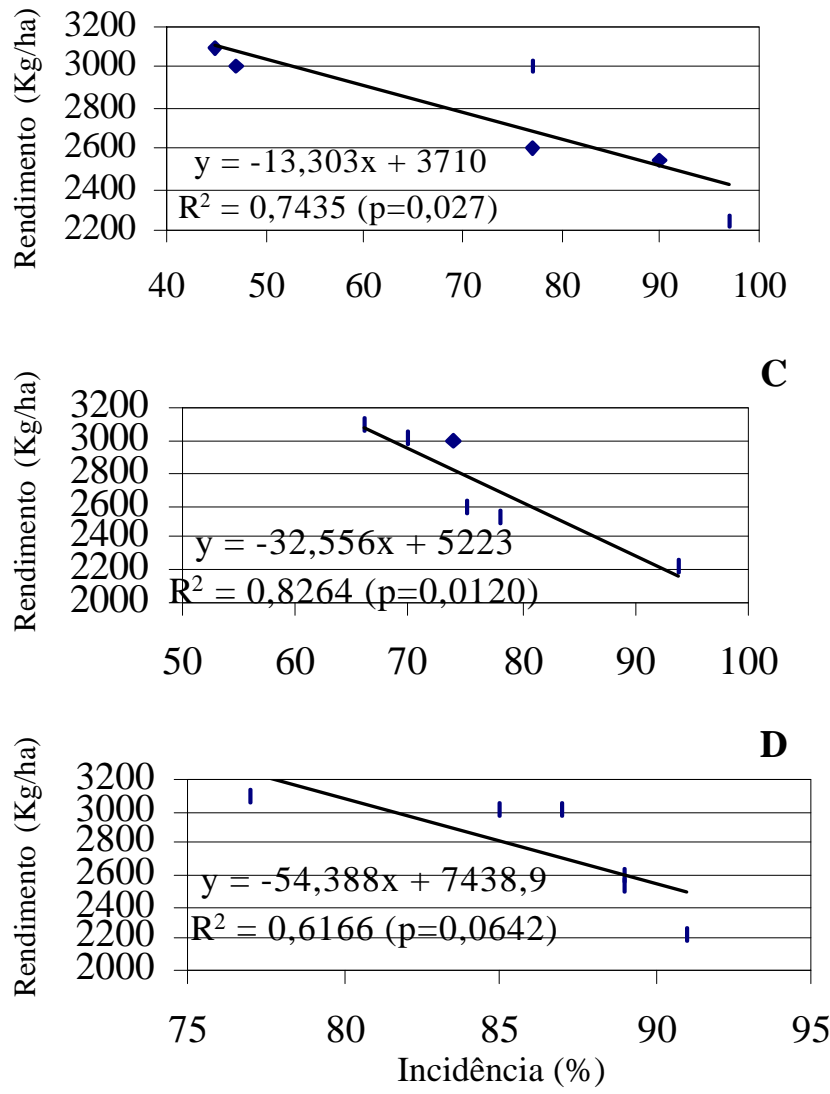

FIG. 1 - Relação entre o rendimento de grãos e a incidência foliar do oídio (Blumeria graminis f.sp. hordei) em quatro estádios fenológicos da cevada (Hordeum vulgare) cultivar BR 2: A - Afilhamento; B Elongação; C - Emborrachamento; e D - Floração.

\& Norton (1984) para o cálculo do limiar de dano econômico do oídio, em cultivares de cevada com suscetibilidade semelhante ao BR 2.

$\mathrm{Na}$ continuidade desse trabalho, estudos devem ser conduzidos para testar o modelo obtido com cultivares com diferentes reações ao oídio. O modelo de ponto crítico gerado, tomando-se como base a equação do afilhamento, tem sido utilizado por produtores do Sul do Brasil para calcular o limiar de dano econômico para o oídio em cevada. Como a doença surge a partir dos primeiros estádios de desenvolvimento fenológico do hospedeiro, sugere-se que se utilize a função obtida para o afilhamento, embora essa tenha $\mathrm{R}^{2}$ semelhante a do afilhamento. 


\section{REFERÊNCIAS BIBLIOGRÁFICAS}

BERGAMIN FILHO, A. \& AMORIM, L. Doenças de plantas tropicais: epidemiologia e controle econômico. São Paulo: Ed. Agronômica Ceres, 1996.

CASA, R.T., HOFFMANN, L.L., PANISSON, E., MENDES, C. \& REIS, E.M. Eficácia de fungicidas no controle do oídio em trigo. Fitopatologia Brasileira 26:444. 2001. (Resumo).

MAHTRE, D.E. Compendium of barley diseases. St. Paul. APS Press. The American Phytopathological Society. 1977.

MUNFORD, J.D. \& NORTON, G.A. Economics of decision making in pest management. Annual Review Entomology 29:157-174. 1984.

RECOMENDAÇÕES. Reunião Anual de Pesquisa de Cevada, 19,
1999. Passo Fundo. Recomendações da Comissão de Pesquisa de Cevada para o cultivo de cevada cervejeira em 1999 e 2000. Passo Fundo: Embrapa Trigo, Documentos 1, 1999.

REIS, E.M., CASA, R.T., HOFFMANN, L.L. \& MENDES, C. Effect of leaf rust on wheat grain yield. Fitopatolologia. Brasileira 25:67-71. 2000.

SAH, D.N. \& MacKENZIE, D.R. Methods of generating different levels of disease epidemics in loss experiments. In: Teng, P.S. (Ed.) Crop loss assessment and pest management. St. Paul: The American Phytopathological Society, 1987. pp.9095.

ZADOKS, J.C., CHANG, T.T. \& KONZAK, C.F. A decimal code for the growth stages of cereals. Weed Research 14:415-421. 1974. 